\title{
Correspondence Analysis of Soil around Micropile Composite Structures under Horizontal Load
}

\author{
Hai Shi, ${ }^{1}$ Mingzhou Bai, ${ }^{1,2}$ Chao Li, ${ }^{1,3}$ Yunlong Zhang, ${ }^{1}$ and Gang Tian' \\ ${ }^{1}$ Beijing Jiaotong University, No. 3, Shangyuancun, Haidian District, Beijing 100044, China \\ ${ }^{2}$ Beijing Key Laboratory of Track Engineering, Beijing, China \\ ${ }^{3}$ Beijing Engineering and Technology Research Center of Rail Transit Line Safety and Disaster Prevention, Beijing, China
}

Correspondence should be addressed to Hai Shi; 516519566@qq.com

Received 27 June 2015; Accepted 1 September 2015

Academic Editor: Fazal M. Mahomed

Copyright (C) 2015 Hai Shi et al. This is an open access article distributed under the Creative Commons Attribution License, which permits unrestricted use, distribution, and reproduction in any medium, provided the original work is properly cited.

\begin{abstract}
The current approach, which is based on conformal transformation, is to map micropile holes in comparison with unit circle domain. The stress field of soil around a pile plane, as well as the plane strain solution to displacement field distribution, can be obtained by adopting complex variable functions of elastic mechanics. This paper proposes an approach based on Winkler Foundation Beam Model, with the assumption that the soil around the micropiles stemmed from a series of independent springs. The rigidity coefficient of the springs is to be obtained from the planar solution. Based on the deflection curve differential equation of Euler-Bernoulli beams, one can derive the pile deformation and internal force calculation method of micropile composite structures under horizontal load. In the end, we propose reinforcing highway landslides with micropile composite structure and conducting on-site pile pushing tests. The obtained results from the experiment were then compared with the theoretical approach. It has been indicated through validation analysis that the results obtained from the established theoretical approach display a reasonable degree of accuracy and reliability.
\end{abstract}

\section{Introduction}

Generally, the diameter of a micropile is about $70-300 \mathrm{~mm}$ in a small diameter filling pile [1]. The slenderness ratio is relatively big. Its preliminary application and exploitation were explored by Fondedile in Italy [2]. Micropile composite structures refer to antislide structures that are composed of several, miniature, and single piles with a cap lid at the pile tip, which jointly bears the horizontal load [3]. The structure adeptly adapts to shifting terrain during construction with small vibration and noise caused by the construction. It is characterized by a small pile diameter, rapid construction, and flexible piles. Thus, it has been widely used in building reinforcements, shake-proof, foundation underpinning, foundation excavation support, landslide control, and other types of engineering found in buildings [4-6].

Previous research on micropile structure mainly discussed ground stabilization, building and rectification, and so forth at vertical load bearing, which was specific to internal force deformation calculations, an analysis of micropiles, and the internal force calculation of a combination of micropile groups [7-9]. The initial research yielded some achievements. Cantoni et al. [10] proposed a design and calculation method based on reticular micropiles, working under the assumption that the retaining structure would need to be complex; when Macklin designed the anchorage retaining wall, he simplified it as gravity retaining walls in order to analyze the internal force of the micropile [11]; Feng et al. [12] proposed an interaction analysis model for the pile-rock soil and masspiles found in flat micropile systems; they also established a mechanical model to calculate the internal force and deformation of a micropile system using a finite element method; Juran et al. [1] proposed a design approach using a mesh micropile reinforced slope, by assuming that the dense composite strengthening body formed by reticular micropiles, the internal soil mass, and the internal system were not subjected to tensile stress; furthermore, Brown and Shie [13] calculated a pile's internal force by applying 
a nonlinear, elastic-plastic subgrade reaction method (called the $p$ - $y$ curve method). However, there was less research on micropile structures under horizontal load. At present, most of the previously discussed engineering designs of micropiles adopt a calculation approach of specific to normal, antislide piles. However, the force model and design calculation theory of micropile composite structure have not been perfected yet. Establishing a calculation mode suitable for micropile composite structure and proposing a reasonable calculation method are urgently needed. Thus, this paper further explores research that capitalizes on this missed opportunity.

This paper discusses an analytical solution to stress and displacement distribution under horizontal load, based on the mechanics theory of two-dimensional elastic complex functions. Using the Winkler Foundation Beam Model, this paper assumes that the soil around a micropile stems from a series of independent springs. The rigidity coefficient of a spring can be obtained using the planar solution. After that, based on the deflection curve of the differential equation of an Euler-Bernoulli beam, the pile deformation and internal force calculation methods of a micropile composite structure under horizontal load can be derived using two modes, namely, by fixing one end, with the other end sliding, as well as fixing both ends. In the end, the paper suggests reinforcing highway landslides using micropile composite structures and conducting on-site pile pushing tests. The results obtained from the experiment have been compared to the theoretical approach to verify the accuracy and reliability of the theoretical approach.

\section{Establishment of the Plane Strain Solution Model of Micropiles}

2.1. Description of the Problem. Then, researching the effects of horizontal load on the micropiles, it is important to consider the internal force and deformation analysis of rigid disc hole structure around the semi-infinite space surface at the $Z$ plane (rectangular coordinate system). As shown in Figure 1, the $R$ region is a region of semi-infinite space, except for the disc-structure, and $a$ is the distance between the soil around the pile and the center of the pile; $r$ is the radius of the disc-structure; and $F$ is the horizontal load applied in the center of the pile ( $F_{x}$ is $x$ component of direction; $F_{y}$ is $y$ component of direction). It is assumed that $u_{0}$ is the displacement under horizontal load applied in the center of the pile.

2.2. Fundamental Assumption of the Mechanical Model. While obtaining the stress field of the soil around the pile and the plane strain solution of the displacement field distribution by adopting the complex variable functions of plane elastic mechanics, the following assumptions are made:

(1) While establishing a strain model of two-dimensional complex elastic mechanics, since the rigidity of the microsteel pile is bigger than that around the pile, assume that mini micropiles and cross section around the piles are rigid disc hole structures.

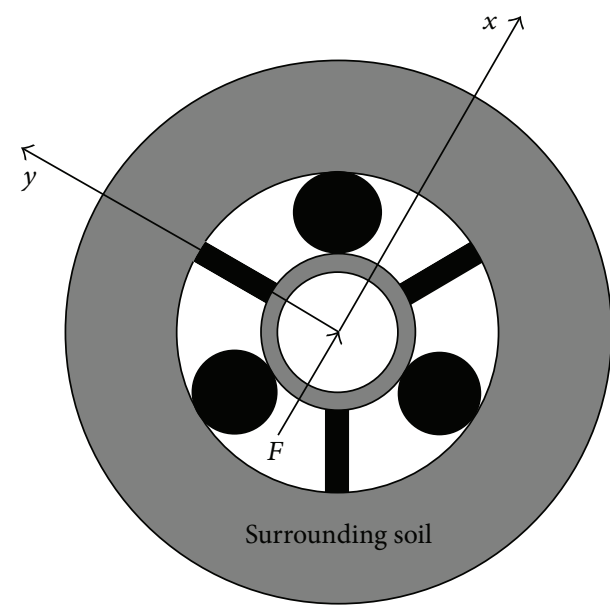

Figure 1: Mechanical model of micropile-soil.

(2) Assume that the deformation of the soil around the pile presents a tendency of elastic variation under horizontal load.

(3) Compare the deformation of the micropile and the soil around the pile under horizontal load.

2.3. Basic Control Equation. According to the complex variable function of plane elastic mechanics, the complex analytic function of stress and displacement components at $R$ region are to be expressed in $\varphi_{1}(x)$ and $\psi_{1}(x)$; then [14],

$$
\begin{aligned}
\sigma_{x}+\sigma_{y} & =4 \operatorname{Re}\left[\varphi_{1}^{\prime}(z)\right] \\
\sigma_{y}-\sigma_{x}+2 i \tau_{x y} & =2\left[\bar{z} \varphi_{1}^{\prime \prime}(z)+\psi_{1}^{\prime}(z)\right] \\
2 G(u+i v) & =\kappa \varphi(\xi)-\overline{\varphi_{1}^{\prime}(\xi)} \frac{\omega(\xi)}{\overline{\omega^{\prime}(\xi)}}-\overline{\psi(\xi)}
\end{aligned}
$$

where $z$ is any point on the micropile hole, $\sigma_{x}, \sigma_{y}$, and $\tau_{x y}$ are the stress and strain component of any point, Re separates the real part and imaginary part in $\kappa=3-4 \mu$, Plane strain; $(3-\mu) /(1+\mu)$, Plane stress, and $G=E / 2(1+\mu)$, where $E$ is modulus of elasticity and $\mu$ is the Poisson ratio.

The analytic function and expression $\varphi_{1}(x)$ and $\psi_{1}(x)$ under stress at infinity bounded conditions are as follows:

$$
\begin{aligned}
\varphi_{1}(z)= & -\frac{1}{2 \pi(1+\kappa)}\left(F_{x}+i F_{y}\right) \ln z+(B+i C) z \\
& +\varphi_{1}^{0}(z), \\
\psi_{1}(z)= & \frac{1}{2 \pi(1+\kappa)}\left(F_{x}-i F_{y}\right) \ln z+\left(B^{\prime}+i C^{\prime}\right) z \\
& +\psi_{1}^{0}(z),
\end{aligned}
$$

where $B, B^{\prime}$, and $C^{\prime}$, respectively, represent the depth of the tunnel, the bulk density of the surrounding rock, and the relationship of the lateral pressure coefficient and the surrounding rock stress. In this equation, $\kappa$ is positive integer. 
$\varphi_{1}^{0}(z)$ and $\psi_{1}^{0}(z)$ are the analytic function of the points in the neighborhood located at infinity. Where $B=\left(\sigma_{x}^{\infty}+\sigma_{y}^{\infty}\right) / 4$, $B^{\prime}=\left(\sigma_{y}^{\infty}-\sigma_{x}^{\infty}\right) / 2 ; C^{\prime}=\tau_{x y}^{\infty}, \sigma_{x}^{\infty}, \sigma_{y}^{\infty}$, and $\tau_{x y}^{\infty}$ is the stress located at infinity.

According to the analytic function under complex variables functions at bounded conditions, the displacement and stress boundary conditions are as follows:

The condition of stress boundary: $i \int_{A}^{B}\left(F_{x}+i F_{y}\right) d s$

$$
=\varphi_{1}(z)+z \overline{\varphi_{1}^{\prime}(z)}+\overline{\psi_{1}(z)},
$$

The condition of displacement boundary: $\kappa \varphi_{1}(z)$

$$
-z \overline{\varphi_{1}^{\prime}(z)}-\overline{\psi_{1}(z)}=2 G(u+i v) .
$$

2.4. Conformal Mapping. One must map the micropile orifice to unit annulus. The semi-infinite space orifice within $Z$ plane can be converted to within the plane $\xi$ after conformal mapping as shown in Figure 2. Then, the mapping function of zone $R$ after conformal mapping is shown in [15]. Therefore,

$$
z=\omega(\xi)=-i a \frac{1-\alpha^{2}}{1+\alpha^{2}} \frac{1-\xi}{1+\xi},
$$

where any point $\xi$ located in the $\xi$ plane is expressed as polar coordinates; that is, $\xi=\rho e^{i \theta}$ and $\alpha$ is a parameter determined by $a$ and $r$ :

$$
\frac{r}{a}=\frac{2 a}{1+a^{2}}
$$

After transforming the function at plane $z$ to the function of $\xi$, the stress and displacement component will change to [16]

$$
\begin{aligned}
& \sigma_{\rho}+\sigma_{\theta}=\sigma_{x}+\sigma_{y}=4 \operatorname{Re}[\Phi(\xi)] \\
& \sigma_{x}-\sigma_{y}+2 i \tau_{x y} \\
& =\frac{2 \xi^{2}}{\rho^{2} \omega^{\prime}(\xi)}\left[\overline{\omega(\xi)} \Phi^{\prime}(\xi)+\omega^{\prime}(\xi) \Psi(z)\right], \\
& 2 G(u+i v)=\kappa \varphi(\xi)-\overline{\varphi_{1}^{\prime}(\xi)} \frac{\omega(\xi)}{\overline{\omega^{\prime}(\xi)}}-\overline{\psi(\xi)},
\end{aligned}
$$

where $z=\omega(\xi), \Phi(\xi)=\varphi_{1}^{\prime}(z)$, and $\Psi(\xi)=\psi_{1}^{\prime}(z)$. From formula (6), it is detected that, in order to get the stress and displacement values through using the fundamental equation, tone has to solve the complex function and obtain the solution to $\varphi_{0}(\xi)$ and $\psi_{0}(\xi)$.

2.5. Solution to Displacement $u_{0}$ under Horizontal Load. (1) According to the plane displacement boundary conditions of micropile-soil structure, the following can be seen from the assumed conditions.

The displacement boundary conditions can be divided as follows: infinity to pile core position, namely, $z=\bar{z}$; so

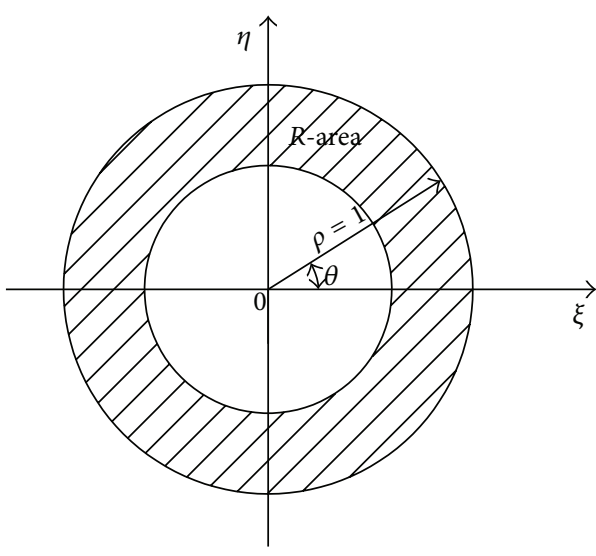

FIGURE 2: Plane of conformal transformation.

the soil mass will not cause direct impact on pile deformation, whereas displacement exists at the contact surface of the pile hole boundary and soil mass, namely, $|z+i a|=r$. The strain of the micropiles soil structure to plane $\kappa=3-4 \mu$ can be seen in formula (3). In other words, the displacement boundary is as follows:

$$
\begin{aligned}
& {\left[(3-4 \mu) \varphi(\xi)-\omega(\xi) \frac{\overline{\varphi^{\prime}(\xi)}}{\overline{\omega^{\prime}(\xi)}}-\overline{\psi(\xi)}\right]_{s_{0}}} \\
& =\frac{E}{1+\mu}(u+i v), \\
& {\left[(3-4 \mu) \varphi(\xi)-\omega(\xi) \frac{\overline{\varphi^{\prime}(\xi)}}{\overline{\omega^{\prime}(\xi)}}-\overline{\psi(\xi)}\right]_{s_{1}}=0,}
\end{aligned}
$$

where $s_{1}$ is distance between the soil around the pile and the center of the pile and $s_{0}$ is the boundary curve of the pile hole.

When the function of the $z$ plane is transformed into a function of the $\xi$ plane, $z=\omega(\xi), \Phi(\xi)=\varphi_{1}^{\prime}(z)$, and $\Psi(\xi)=$ $\psi_{1}^{\prime}(z)$ are substituted into formula (2) to get the following:

$$
\begin{aligned}
\varphi(\xi)= & -\frac{1}{8 \pi(1-\mu)}\left(\sum F_{x}+i \sum F_{y}\right) \ln \omega(\xi) \\
& +(B+i C) \omega(\xi)+\varphi_{0}(\xi), \\
\psi(\xi)= & \frac{1}{8 \pi(1-\mu)}\left(\sum F_{x}-i \sum F_{y}\right) \ln \omega(\xi) \\
& +\left(B^{\prime}+i C^{\prime}\right) \omega(\xi)+\psi_{0}(\xi),
\end{aligned}
$$

where $\varphi_{0}(\xi)=\sum_{k=0}^{n} a_{k} \xi^{-k}$ and $\psi_{0}(\xi)=\sum_{k=0}^{n} b_{k} \xi^{-k}$. From the given situation, one can obtain $\sum F_{x}=F, \sum F_{y}=0$, and $B=$ $C=C^{\prime}=B^{\prime}=0$. When the initial conditions are substituted into formula (8), one can get the following:

$$
\begin{aligned}
& \varphi(\xi)=-\frac{1}{8 \pi(1-\mu)} F \ln \omega(\xi)+\varphi_{0}(\xi), \\
& \psi(\xi)=\frac{1}{8 \pi(1-\mu)} F \ln \omega(\xi)+\psi_{0}(\xi) .
\end{aligned}
$$


By substituting formula (9) into the displacement boundary condition, formula (7), it can be derived that

$$
\begin{aligned}
& {\left[(3-4 \mu) \varphi_{0}(\xi)-\frac{\omega(\xi)}{\overline{\omega^{\prime}(\xi)}} \overline{\varphi_{0}^{\prime}(\xi)}-\overline{\psi_{0}(\xi)}\right]=f} \\
& {\left[(3-4 \mu) \varphi_{0}(\xi)-\frac{\omega(\xi)}{\overline{\omega^{\prime}(\xi)}} \overline{\varphi_{0}^{\prime}(\xi)}-\overline{\psi_{0}(\xi)}\right]=f_{1}}
\end{aligned}
$$

where

$$
\begin{aligned}
f & =\frac{E}{1+\mu} u_{0}-\frac{F}{8 \pi(1-\mu)}\left[\ln \overline{\omega(\xi)}-\frac{\omega(\xi)}{\overline{\omega(\xi)}}\right. \\
& +(3-4 \mu) \ln \omega(\xi)], \\
f_{1} & =-\frac{F}{8 \pi(1-\mu)}\left[\ln \overline{\omega(\xi)}-\frac{\omega(\xi)}{\overline{\omega(\xi)}}\right. \\
& +(3-4 \mu) \ln \omega(\xi)] .
\end{aligned}
$$

Through the simultaneous application of the boundary conditions of the two equations found in formula (10), the expression of $\varphi_{0}(\xi)$ and $\psi_{0}(\xi)$ can be derived (including the unknown displacement of $u_{0}$ ).

(2) Considering the micropile hole boundary, namely, for the boundary conditions $s_{0}, \sigma=e^{i \theta}$, the stress boundary conditions are to be expressed with components under the orthogonal curvilinear coordinate system at the $z$ plane. Namely,

$$
\left[(3-4 \mu) \varphi_{0}(\sigma)-\frac{\omega(\sigma)}{\overline{\omega^{\prime}(\sigma)}} \overline{\varphi_{0}^{\prime}(\sigma)}-\overline{\psi_{0}(\sigma)}\right]=f_{0}
$$

The Cauchy integral operator $(1 / 2 \pi i) \oint(d \sigma /(\sigma-\xi))$ at both ends of the formula above can be obtained:

$$
\begin{gathered}
\frac{(3-4 \mu)}{2 \pi i} \oint \frac{\varphi_{0}(\sigma) d \sigma}{\sigma-\xi}-\frac{1}{2 \pi i} \oint \frac{\omega(\sigma)}{\overline{\omega^{\prime}(\sigma)} \frac{\overline{\varphi_{0}^{\prime}(\sigma)}}{\sigma-\xi} d \sigma} \\
-\frac{1}{2 \pi i} \oint \frac{\overline{\psi_{0}(\sigma)}}{\sigma-\xi} d \sigma=\frac{1}{2 \pi i} \oint \frac{f_{0}}{\sigma-\xi} d \sigma .
\end{gathered}
$$

In formula (13), $\oint\left(\varphi_{0}(\sigma) d \sigma /(\sigma-\xi)\right)=-\varphi_{0}(\xi)$, $(1 / 2 \pi i) \oint\left(\overline{\psi_{0}(\sigma)} /(\sigma-\xi)\right) d \sigma=0$; so by substituting into formula (13), one can find $\varphi_{0}(\xi)$.

Similarly, according to formula (12), the value of $\psi_{0}(\xi)$ can be obtained by taking conjugation at both sides and then applying the Cauchy integral operator. Thus, the information can be simultaneously obtained by combining formula (10), to get the value of $u_{0}$.
2.6. Solution to $\varphi_{0}(\xi)$ and $\psi_{0}(\xi)$. To obtain the boundary conditions of a miniature pile, make $\xi=\sigma \rho$ and unfold $\varphi(\xi)$ and $\psi(\xi)$ in a Laurent series form; namely [17],

$$
\begin{aligned}
& \varphi(\xi)=a_{0}+\sum_{k=1}^{n} a_{k} \xi^{k}+\sum_{k=1}^{n} b_{k} \xi^{-k} \\
& \psi(\xi)=c_{0}+\sum_{k=1}^{n} c_{k} \xi^{k}+\sum_{k=1}^{n} d_{k} \xi^{-k}
\end{aligned}
$$

Depending on formula (4), one can get the following:

$$
\frac{\omega(\sigma)}{\overline{\omega^{\prime}(\sigma)}}=-\frac{1}{2} \frac{(1+\rho \sigma)(\sigma-\rho)^{2}}{\sigma^{2}(1-\rho \sigma)} .
$$

Using formulas (14) and (15) substituted into boundary conditions $s_{1}$ of formula (7), one can get the following:

$$
\begin{aligned}
& c_{0}=-\overline{a_{0}}-\frac{1}{2} a_{1}-\frac{1}{2} b_{1}, \\
& c_{k}=-\overline{b_{k}}+\frac{1}{2}(k-1) a_{k-1}-\frac{1}{2}(k+1) a_{k+1}, \\
& d_{k}=-\overline{a_{k}}+\frac{1}{2}(k-1) b_{k-1}-\frac{1}{2}(k+1) b_{k+1} .
\end{aligned}
$$

Make $f(\xi)=f(\alpha \sigma)=2 G(u+i v)$ and $f^{*}(\alpha \sigma)=(1-$ $\alpha \sigma) f(\alpha \sigma)=\sum_{k}^{\infty} A_{k} \sigma_{k}$. Formulas (14), (15), and (17)-(19) can be substituted into the boundary conditions $s_{1}$ of formula (7); by eliminating $c_{k}$ and $d_{k}$, one finds $a_{k}$ and $b_{k}$ :

$$
\begin{aligned}
& \left(1-\alpha^{2}\right)(k+1) \overline{a_{k+1}}-\left(\alpha^{2}+\kappa \alpha^{-2 k}\right) b_{k+1} \\
& =\left(1-\alpha^{2}\right) k \overline{a_{k}}-\left(1+\kappa \alpha^{-2 k}\right) b_{k}+A_{-k} \alpha^{k}, \\
& \left(1+\kappa \alpha^{2 k+2}\right) \overline{a_{k+1}}+\left(1-\alpha^{2}\right)(k+1) b_{k+1} \\
& \quad=\alpha^{2}\left(\alpha^{2}+\kappa \alpha^{2 k}\right) \overline{a_{k}}+\left(1-\alpha^{2}\right) k b_{k}+A_{1+k} \alpha^{k+1}, \\
& \left(1-\alpha^{2}\right) \overline{a_{1}}-\left(\kappa+\alpha^{2}\right) b_{1}=A_{0}-(\kappa+1) a_{0}, \\
& \left(1+\kappa \alpha^{2}\right) \overline{a_{1}}+\left(1-\alpha^{2}\right) b_{1}=\overline{A_{1}} \alpha+\alpha^{2}(\kappa+1) \overline{a_{0} .}
\end{aligned}
$$

We simultaneously solved the four formulas in (17) to get all of the coefficients except for $a_{0}$, since $a_{0}$ represents rigid body displacement; thus, no stress will be generated and it can be deemed as 0 . By $k$ times of iteration, one can obtain $a_{k}$; thus, to get $\varphi_{0}(\xi)$ and $\psi_{0}(\xi)$, one must substitute $\varphi_{0}(\xi)$ and $\psi_{0}(\xi)$ in the complex function of the fundamental equation, to ascertain the stress and displacement field of the soil around a pile of micropiles under horizontal load. According to the assumed conditions specified in Sections 2.1 and 2.2, the relationship between horizontal load and the horizontal displacement can be obtained from $K=F / u_{0}$.

\section{Establishment of Pile-Soil Mechanics Model Based on Winkler Foundation Beam}

In most cases, while ministeel tub piles under horizontal load are applied in landslide control and slope reinforcement, 


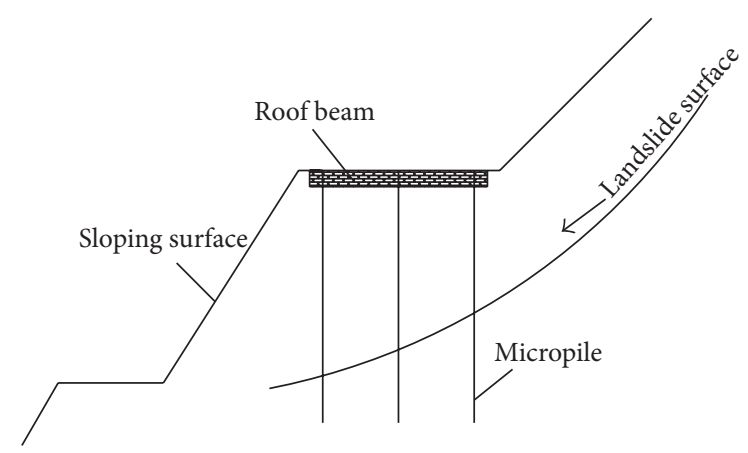

FIGURE 3: Micropile composite structure set on step of slope.

a pile groups' layout will be adopted. Especially for multistage slopes, platforms are available for each grade. Miniature piles can be set at the platform for reinforcement. The multiple, miniature piles that are exposed on the platform can be fixed with a top beam to enhance their sliding resistance force. The micropile layout is shown in Figure 3.

3.1. Model Assumption. While miniature piles are applied for landslide reinforcement, the mechanism can be used to address bigger shearing resistance in miniature pile landslides. Pile-soil structures will resist landslide thrust formed by micropiles as well as the soil mass. For internal calculation, the Winkler low econometric model is adopted. This research assumes that the soil around the micropile has a series of discrete springs and a rigidity coefficient of $K=F / u_{0}$. As shown in Figure 3, since the micropile is fixed at the bed rock below the sliding surface, it is assumed that the sliding surface is as fixed constraint. Due to the fact that the micropile is fixed and connected through a top beam, as compared to miniature pile, the top beam can be deemed as a rigid member. Under the effects of horizontal load, the top beam only experiences horizontal displacement, so the displacement at each pile cap will be the same [18]. Thus, the internal force calculation of the model is shown in Figure 4.

3.2. Internal Force Calculation. According to the fundamental theory of elastic mechanics, the stress and calculation model of a single micropile can be obtained as shown in Figure 5. It is composed of two calculation models, namely, with one fixed and one sliding end under a concentrated load (Figure 5(a)) and with both ends fixed under a uniformly distributed load (Figure 5(b)). Specific to the calculation model found in Figure 4, for three-row micropile structure, the internal force of the micropile $\mathrm{AD}$ is obtained through superposition of Figures 5(a) and 5(b). The internal forces of micropile BE and CF are derived from Figure 5(a).

3.2.1. Solution to Calculation Model with One Fixed and One Sliding End under a Concentrated Load. According to the internal force calculation model specified in Figure 5(a), when considering micropile structures with one fixed end and one sliding end under a concentrated load, the boundary

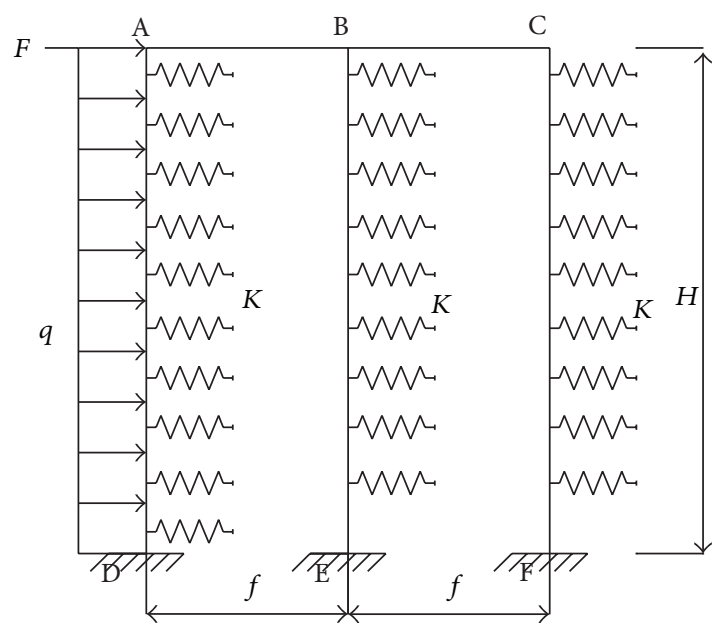

FIGURE 4: Mechanical calculation model of micropile structure.

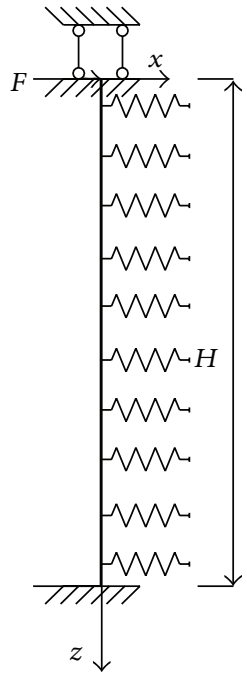

(a)

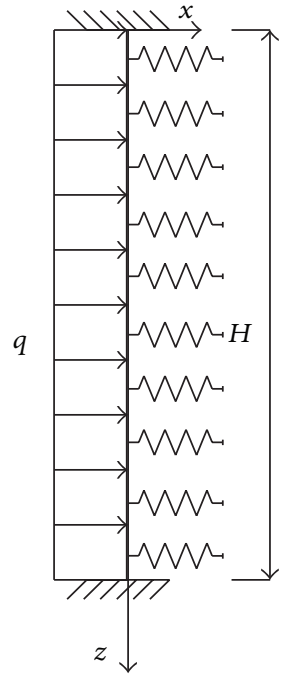

(b)
FIGURE 5: Mechanical calculation model of single micropile.

condition on the top of the micropile is $z=0$; the bending moment is $M=0$; and $F$ is horizontal shear. The boundary condition on the bottom of the micropile is $z=H$, the angle is $\varphi=0$, and the horizontal displacement is $u=0$. The flexural differential equation of an Euler-Bernoulli beam with one fixed and one sliding end is [19]

$$
E I \frac{d^{4} u}{d z^{4}}+K u(z)=0 .
$$

In the formula above, $E$ is the elasticity modulus of the miniature pile, $I$ is the inertia moment of a micropile cross section, $K$ is the rigidity coefficient of an assumed spring, and $u(z)$ is the horizontal displacement of the soil around the pile along the pile body. 


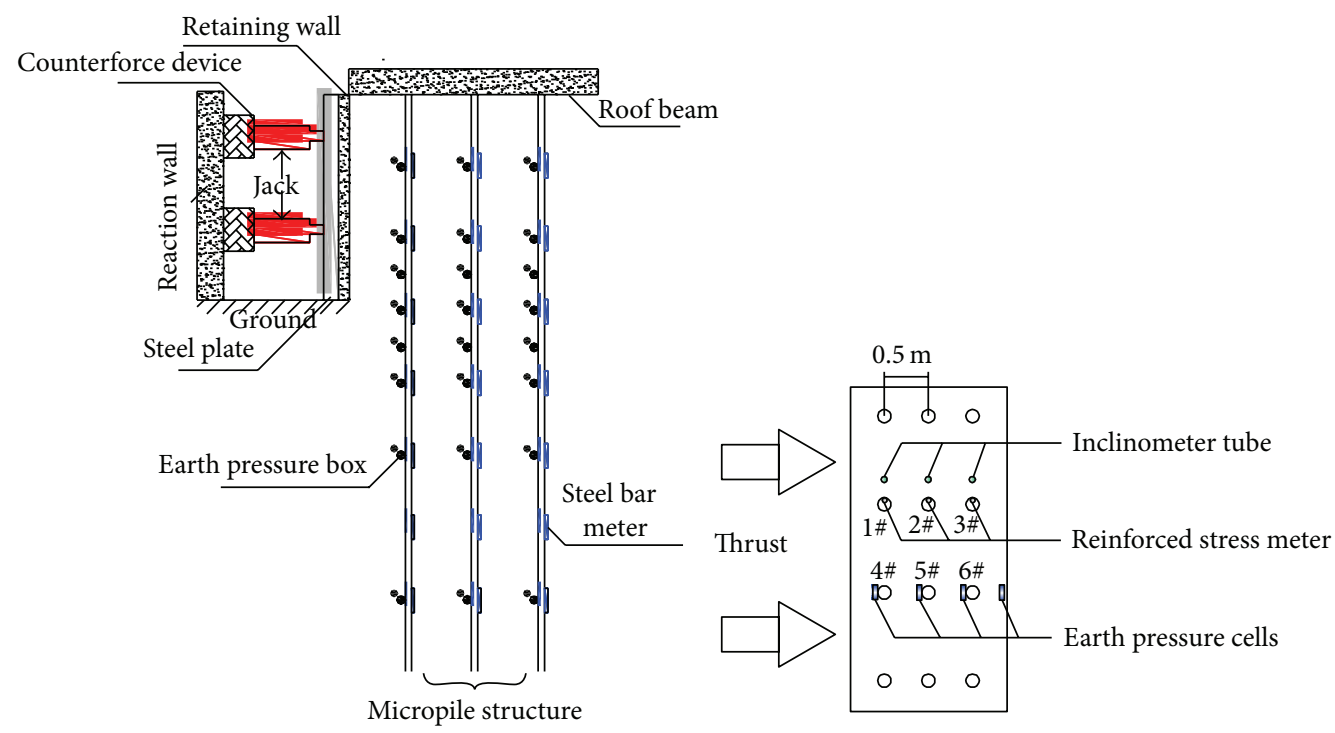

FIGURE 6: The schematic drawing of a test model of micropiles composite structure.

By substituting the boundary conditions in the flexural differential equation (18), the analytical solution can be obtained:

$$
\begin{aligned}
u= & e^{\lambda z}\left[c_{1} \cos (\lambda z)+c_{2} \sin (\lambda z)\right] \\
& +e^{-\lambda z}\left[c_{3} \cos (\lambda z)+c_{4} \sin (\lambda z)\right], \\
M= & 2 \lambda^{2} E I e^{\lambda z}\left[c_{2} \cos (\lambda z)-c_{1} \sin (\lambda z)\right] \\
& +2 \lambda^{2} E I e^{-\lambda z}\left[c_{4} \cos (\lambda z)-c_{3} \sin (\lambda z)\right],
\end{aligned}
$$

where $\lambda=(K / 4 E I)^{1 / 4}$ and $c_{1}, c_{2}, c_{3}$, and $c_{4}$ are the integral constant.

3.2.2. Solution to Calculation Model with Both Ends Fixed under a Uniformly Distributed Load. According to the internal force calculation model specified in Figure 5(b), for micropile structures with both ends fixed under a uniformly distributed load, the flexural differential equation of an EulerBernoulli beam is [18]

$$
E I \frac{d^{4} u}{d z^{4}}+K u(z)=q(z)=0
$$

where $q(z)$ is the uniform load of the soil around the pile. To solve this equation, $\lambda=(K / 4 E I)^{1 / 4}$ can be substituted into formula (19) to get the following:

$$
\frac{d^{4} u}{d z^{4}}+4 \lambda u(z)=\frac{q}{E I}
$$

By substituting the boundary conditions into the flexural differential equation (18), the analytical solution can

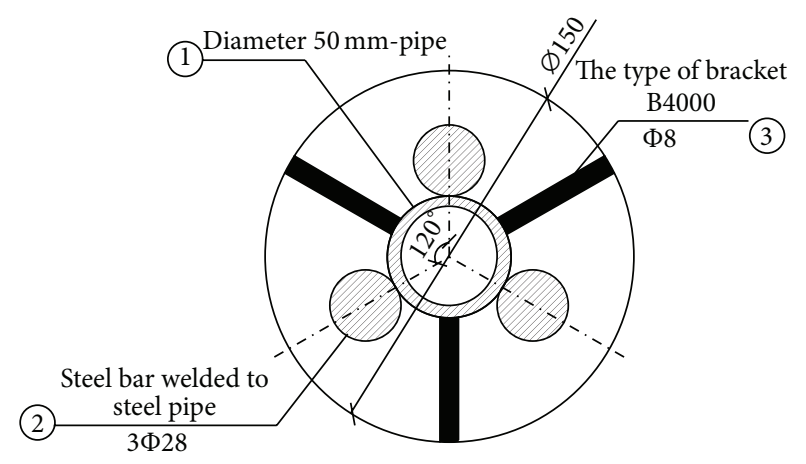

Figure 7: Micropiles sectional drawing.

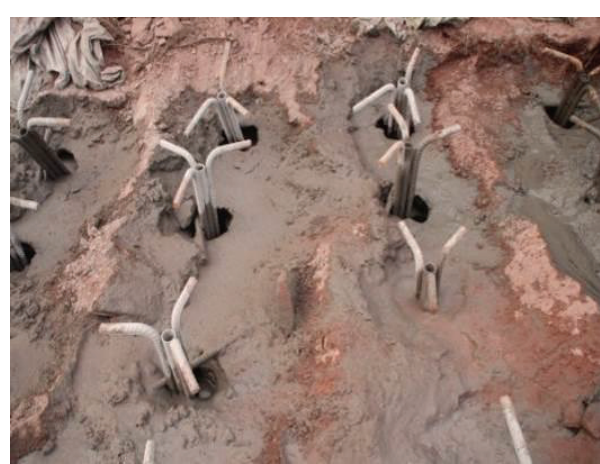

FIGURE 8: The field tests of micropile.

be obtained. The general solution $q(z)=0$ and special connection is $q(z)$; that is,

$$
\begin{aligned}
u= & e^{\lambda z}\left[c_{1} \cos (\lambda z)+c_{2} \sin (\lambda z)\right] \\
& +e^{-\lambda z}\left[c_{3} \cos (\lambda z)+c_{4} \sin (\lambda z)\right]+\frac{q}{K} .
\end{aligned}
$$



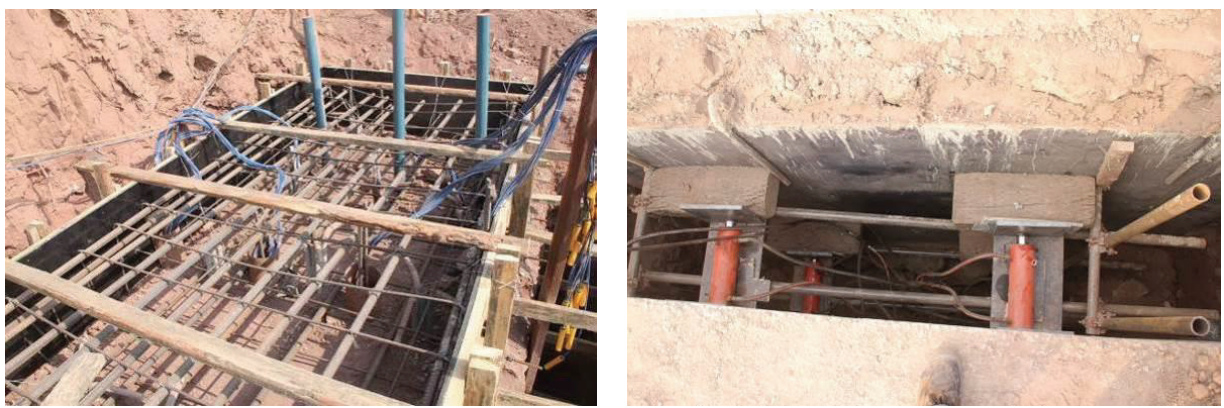

FIgURE 9: The horizontal static load test of micropiles.

3.2.3. The Determination of the Elastic Modulus (E). In the previous calculation, $E$ is a crucial parameter, usually determined by laboratory experiment and experimental relationship of previous practice. However, as laboratory experiment, it is very difficult to reproduce the soil pile in live load effect on the stress path, and experiential relationship cannot determine the value of $E$ either as it can be influenced obviously by human interference. Due to the above reason, in this paper, the field test of single pile at the scene of the elastic deformation range was applied. The elastic model value is the inversion analysis through the stress-strain curve, with the basic process described as follows.

Under the load, the micropile is loaded step by step, using the same load increment. Record each time load displacement deformation, therefore, according to the stress-strain curve obtained from test to calculate the value of elastic modulus.

\section{Engineering Practice Analysis and Verification of Pile-Soil Mechanics Model}

4.1. Engineering Examples. In this example, the landslide of a highway is medium type, about $80-100 \mathrm{~m}$ wild and $160 \mathrm{~m}$ long. The front is about $5 \mathrm{~m}$ thick, whereas the central part is $10-15 \mathrm{~m}$ thick and the back part is $3.5-8.0 \mathrm{~m}$ thick. The average thickness of the landslide is about $10 \mathrm{~m}$ and the total volume of landslide is about $160,000 \mathrm{~m}^{3}$. The landslide demonstrates typical factors with the slope facing the empty and the steep slope. The features of landslide appearance are obvious: the back has tensile cracks and the two sides have pinnate cracks. The front is flanked by a shear seam with a ballooning extrusion crack forming and radioactive cracks. Specific to the characteristics of this landslide, it is proposed to adopt a light, retaining structure with a ministeel tub piles composite structure for reinforcement.

\subsection{Establishment of Experiment Process and Numerical Simu-} lation. According to the design requirements, we performed on-site horizontal static load tests within the landslide reinforcement range. We then simulated an action mechanism and stress distribution in the micropile composite structure by adopting a jack to provide load. Through earth pressure cells that were installed before and after the micropile, we were able to monitor the earth pressure variation and the landslide thrust while checking the status of each row of piles. The stress of the miniature piles is measured through a reinforcement meter that was welded on a miniature steel pipe. The pile body deformation was indirectly measured through an inclinometer that was installed on the pile sides. Figure 6 shows the model demonstration diagram.

4.2.1. Experiment Process. The in situ test uses the micropile to determine the rate of reinforcement. The grouting coagulation of the soil strength grade is C25. The micropile length indicates the landslide segment, which is $8 \mathrm{~m}$ long. The pile diameter is $150 \mathrm{~mm}$ and the tube diameter is $50 \mathrm{~mm}$. The main reinforcement pile contains 3 roots, made up of 28 reinforced steel pipes. The microcap sets the C 30 concrete capping beam with a beam that is $0.5 \mathrm{~m}$ high and $1.5 \mathrm{~m}$ wide. In accordance with the requirements for the load test, the test is conducted with a grade 11 effective load, using two gauges to record the data. The average is taken as the final result. On the 12 th level $(96 \mathrm{t})$ load, the counterforce device becomes damaged, indicating the end of the test. The load of the destruction is the horizontal limit load. At the moment when the maximum amount of bending occurs, the steel of the yielding tensile zone is the corresponding load. The micropile section and test process are shown in Figures 7, 8, and 9.

4.2.2. Result Analysis. The rate of pile displacement of each grade of load was obtained through on-site experiments and analysis, as shown in Figures 10 and 11. In Figures 10 and 11, it can be detected that, under horizontal load, the displacement of the micropile composite structure above the sliding surface $(3 \mathrm{~m})$ is more obvious than that below the sliding surface, which indicates that the micropile composite structure presents a tendency to lean forward. Since the pile only leaned $2 \mathrm{~m}$ forward at the base below the sliding surface, the horizontal displacement is basically 0 , which indicates that the anchorage effects at the anchorage section are comparatively better. When consistently increasing the horizontal load, the variable quantities of the displacement of pile top of each row of piles are the same. This consistency in the variable quantities is caused by the lid cap contracting to make the micropile composite structure act as a whole for antisliding by adopting a jack to provide step load. The bending moment and the displacement distribution laws of the three-row piles are similar. A bending moment above $0.25 \mathrm{~m}$ is 0 . No bending deflection of the micropile is generated, due to the constraint 

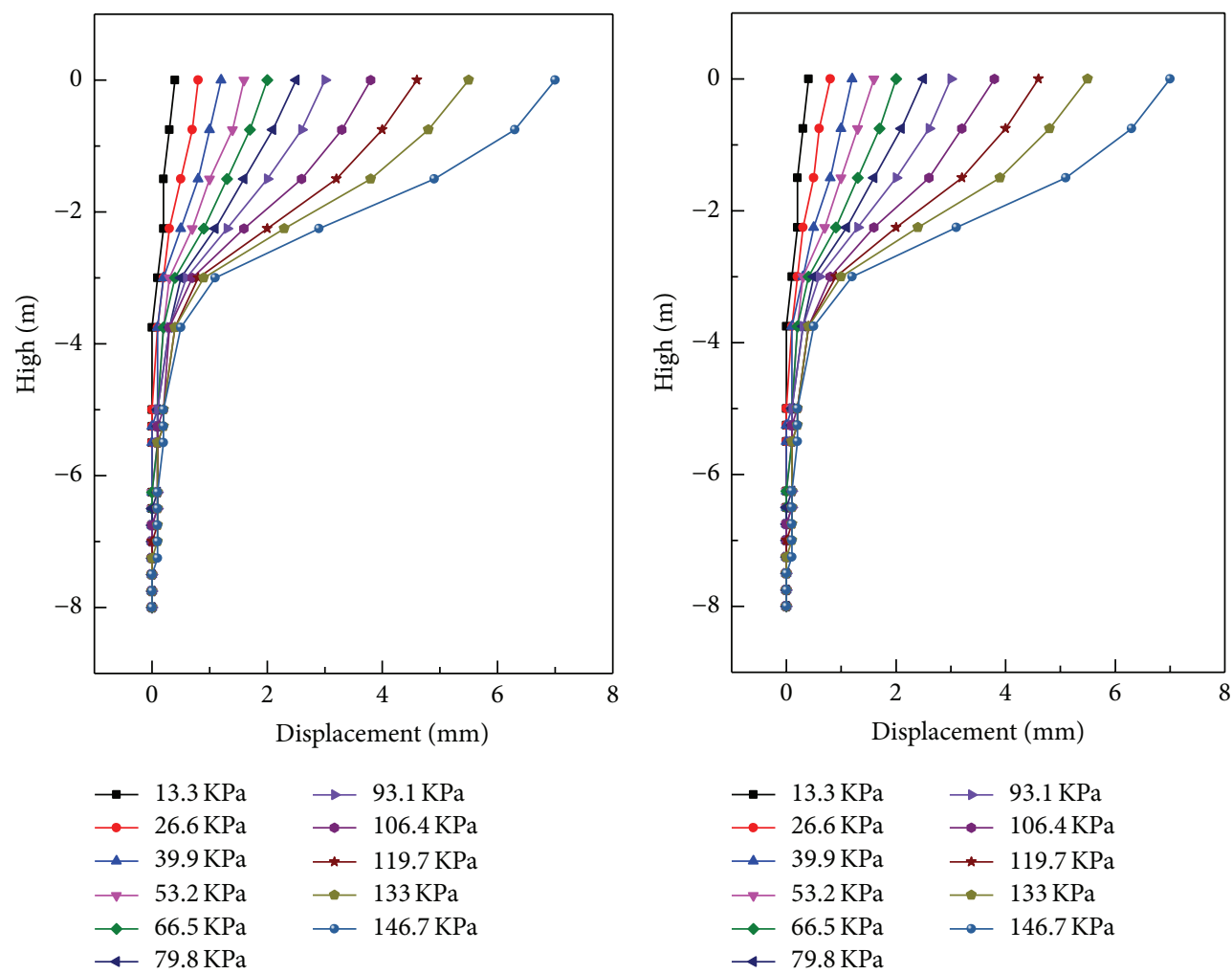

(a) The first row of piles

(b) The second row of piles

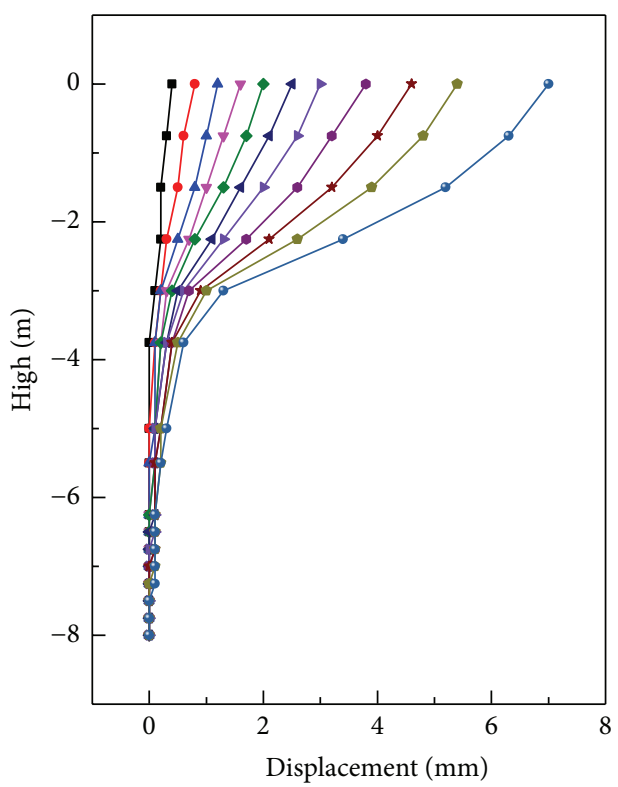

$$
\begin{aligned}
& \rightarrow 13.3 \mathrm{KPa} \rightarrow 93.1 \mathrm{KPa} \\
& \rightarrow 26.6 \mathrm{KPa} \rightarrow 106.4 \mathrm{KPa} \\
& \neg 39.9 \mathrm{KPa} \quad \text { * } 119.7 \mathrm{KPa} \\
& \rightarrow 53.2 \mathrm{KPa} \rightarrow 133 \mathrm{KPa} \\
& \rightarrow 66.5 \mathrm{KPa} \rightarrow 146.7 \mathrm{KPa} \\
& \leftarrow 79.8 \mathrm{KPa}
\end{aligned}
$$

(c) The third row of piles

FIgURE 10: Comparative curves of distribution of pile deflection. 

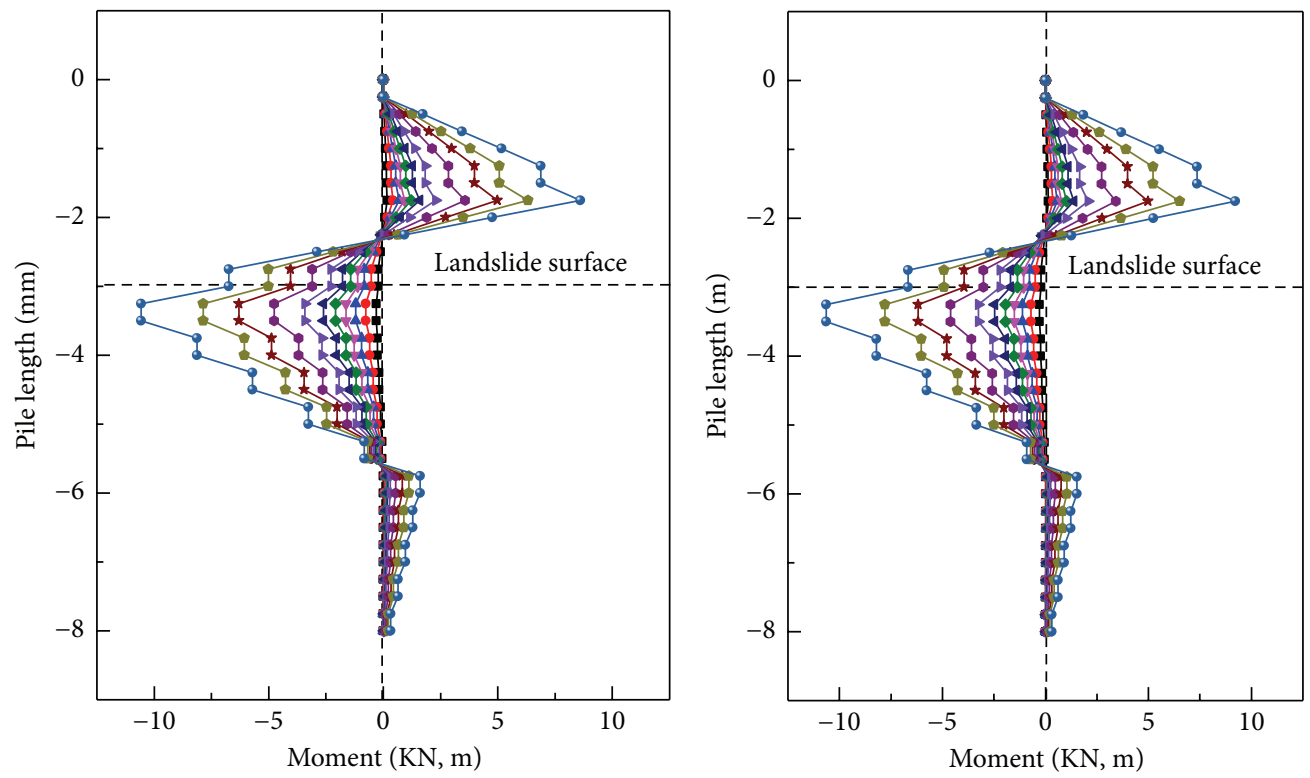

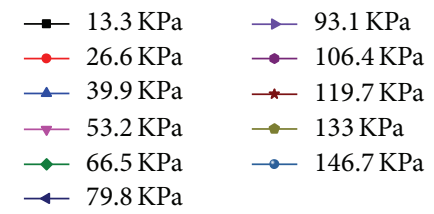

(a) The first row of piles

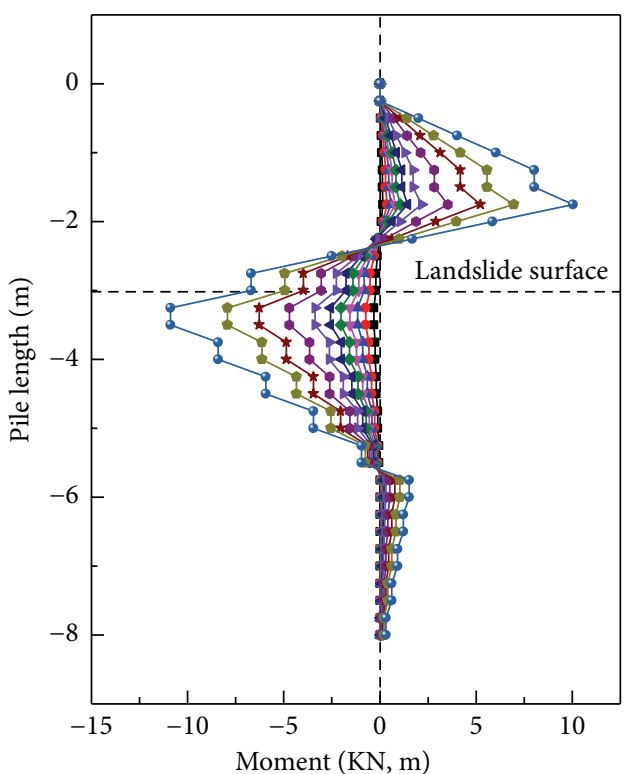

$\begin{array}{ll}\rightarrow 13.3 \mathrm{KPa} & \rightarrow-93.1 \mathrm{KPa} \\ \rightarrow-26.6 \mathrm{KPa} & \rightarrow-106.4 \mathrm{KPa} \\ \leftarrow 39.9 \mathrm{KPa} & \rightarrow 119.7 \mathrm{KPa} \\ \rightarrow-53.2 \mathrm{KPa} & \rightarrow-133 \mathrm{KPa} \\ \rightarrow-66.5 \mathrm{KPa} & \rightarrow-146.7 \mathrm{KPa}\end{array}$

(c) The third row of piles

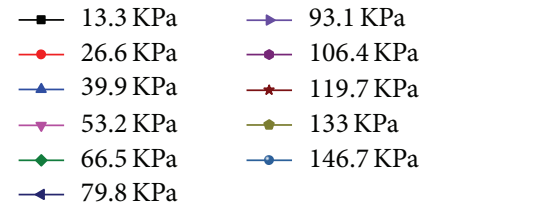

(b) The second row of piles

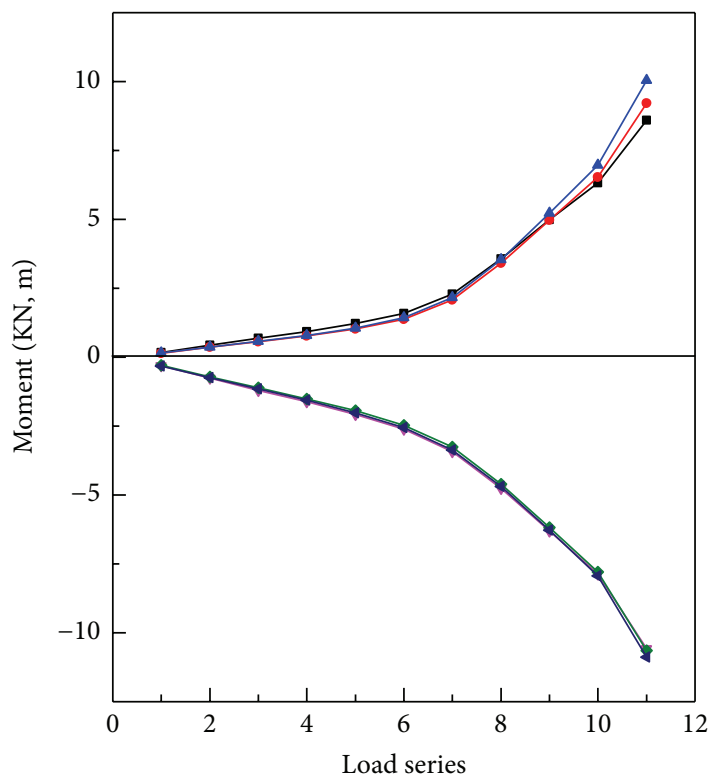

$\rightarrow$ The first row pile $+\rightarrow-$ The first row pile -

$\rightarrow$ The second row pile $+\rightarrow-$ The second row pile -

$\_$The third row pile $+\_$The third row pile -

(d) The maximum positive (negative) moment

FIGURE 11: Comparative curves of distribution of pile model. 


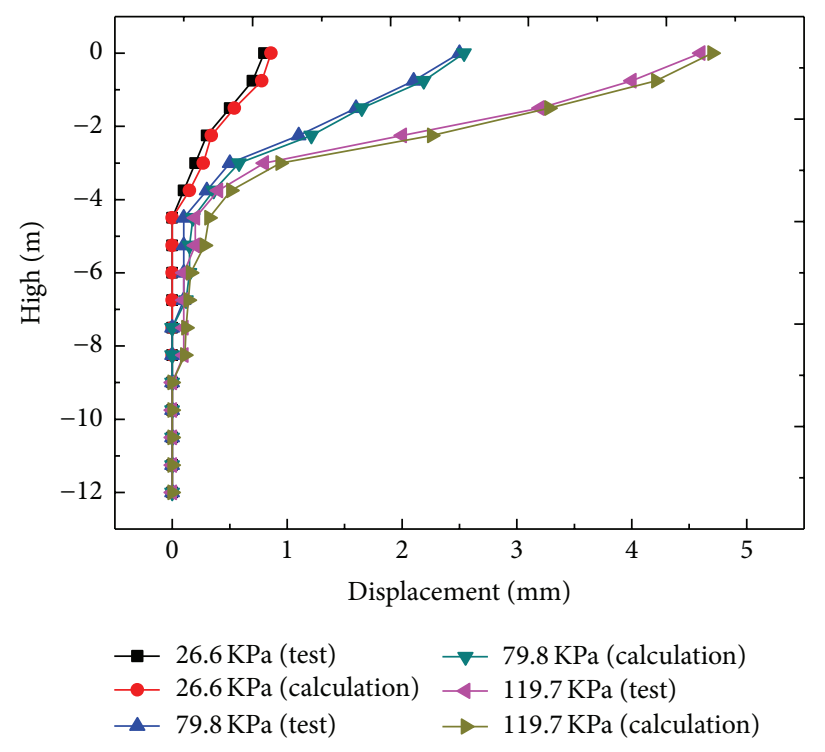

(a) The first row of piles

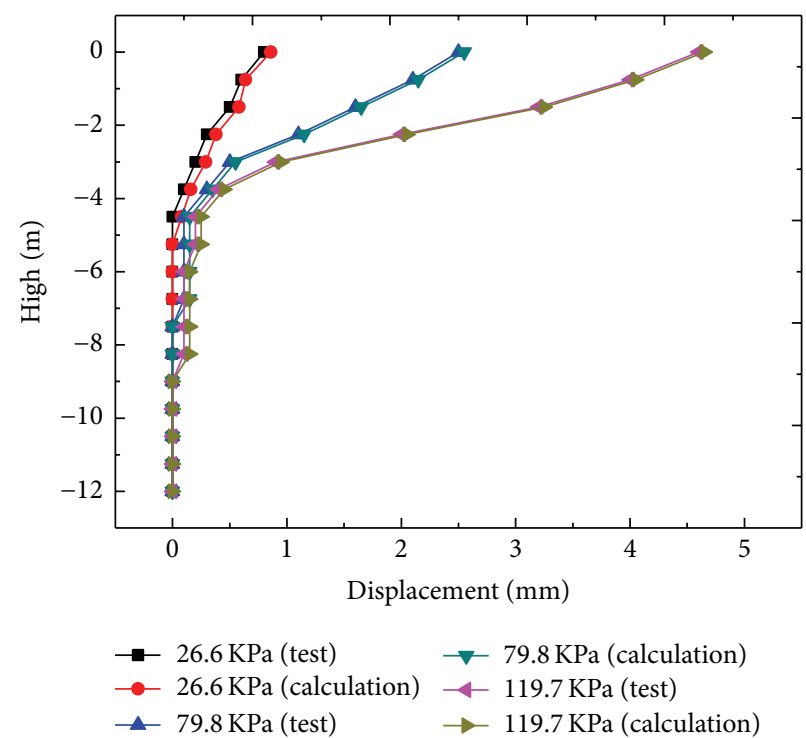

(b) The second row of piles

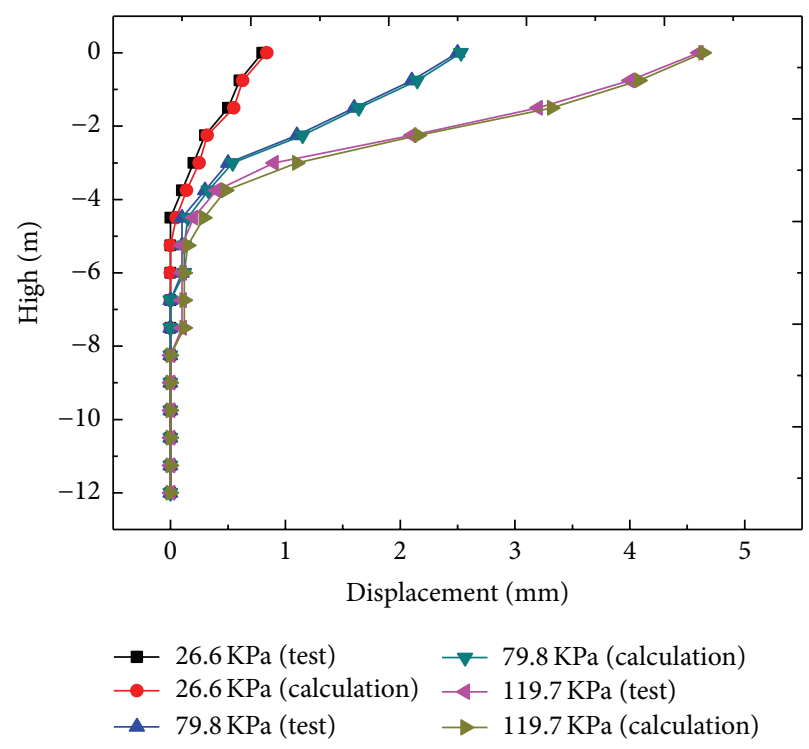

(c) The third row of piles

FIGURE 12: Comparative curves of the distribution of pile deflection.

of the cap lid. The point of contraflexure occurred at $0.9 \mathrm{~m}$ above the sliding surface and $2.5 \mathrm{~m}$ below the sliding surface for the three rows of piles. The maximum sagging moment is at $1 \mathrm{~m}$ above the sliding surface and the maximum hogging moment is at $0.5 \mathrm{~m}$ below the sliding surface. The value of bending moment increases along with the horizontal load. As the horizontal load increased to grades $9-120 \mathrm{KPa}$ (close to the upper limit of the horizontal load of an antislide structure of the micropile combination), the increment of the maximum bending moment (the absolute value) at the third row will be the maximum, followed by that of the second row and then the first row. If each row of piles adopts the same bending strength design without considering the impact of plastic failure on the soil mass between the piles, under the effects of landslide thrust beyond the upper limit of the horizontal load of the micropile combined mechanism, then the sequence for each row of piles is the third row, followed by the second row and the first row.

4.3. Contrastive Analysis to Theoretical Calculation. The proposed approach incorporated the theoretical calculation model of Sections 2 and 3 and the mechanical parameters and conditions of the experiment in order to calculate the displacement of each row of micropiles under $26.6 \mathrm{KPa}$, 79.8 KPa, and 119.7 KPa, as well as the bending moment under 26.6 KPa and 119.7 KPa, as shown in Figures 12 and 13.

By comparing Figures 10 and 12 to Figures 11 and 13, it can be seen that, according to the pile-soil response theory calculation method under horizontal load, the pile displacement and bending moment are similar to the results found 


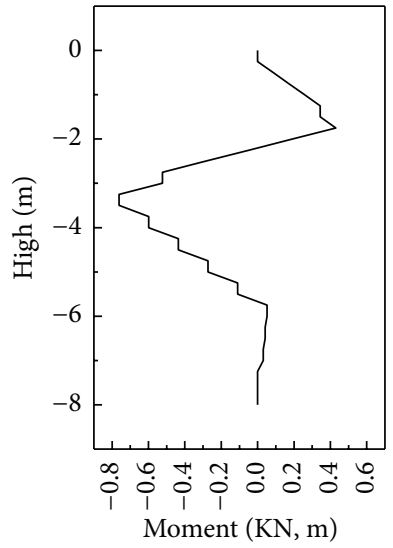

$-26.6 \mathrm{KPa}$ (test)

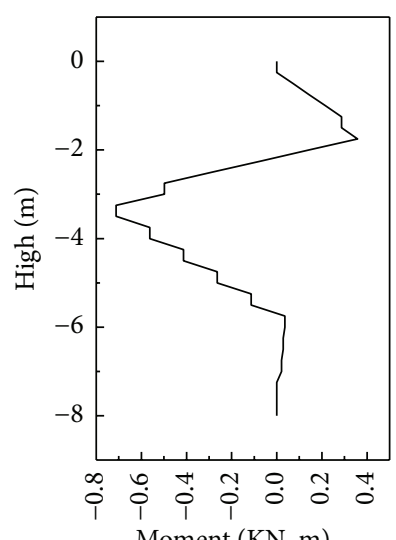

Moment $(\mathrm{KN}, \mathrm{m})$

- $26.6 \mathrm{KPa}$ (test)

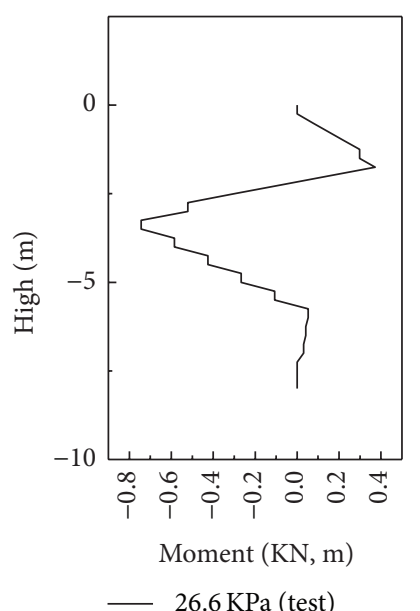

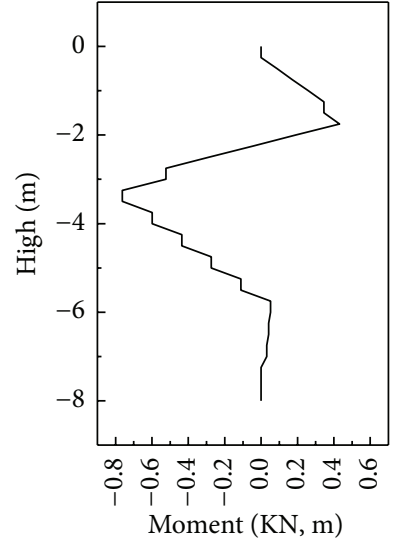

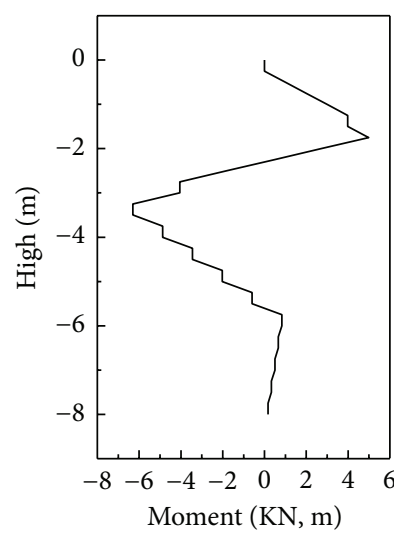

— $26.6 \mathrm{KPa}$ (calculate)

$-119.7 \mathrm{KPa}$ (test)

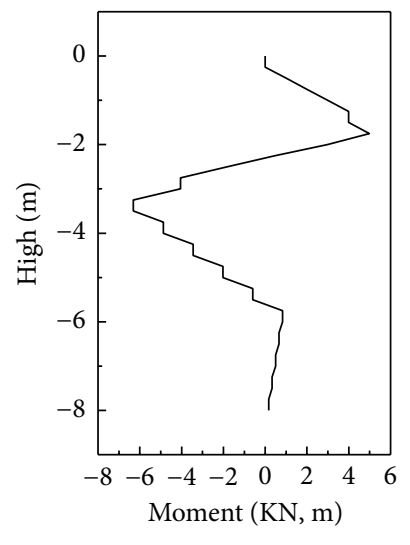

- $119.7 \mathrm{KPa}$ (calculate)

(a) The first row of piles
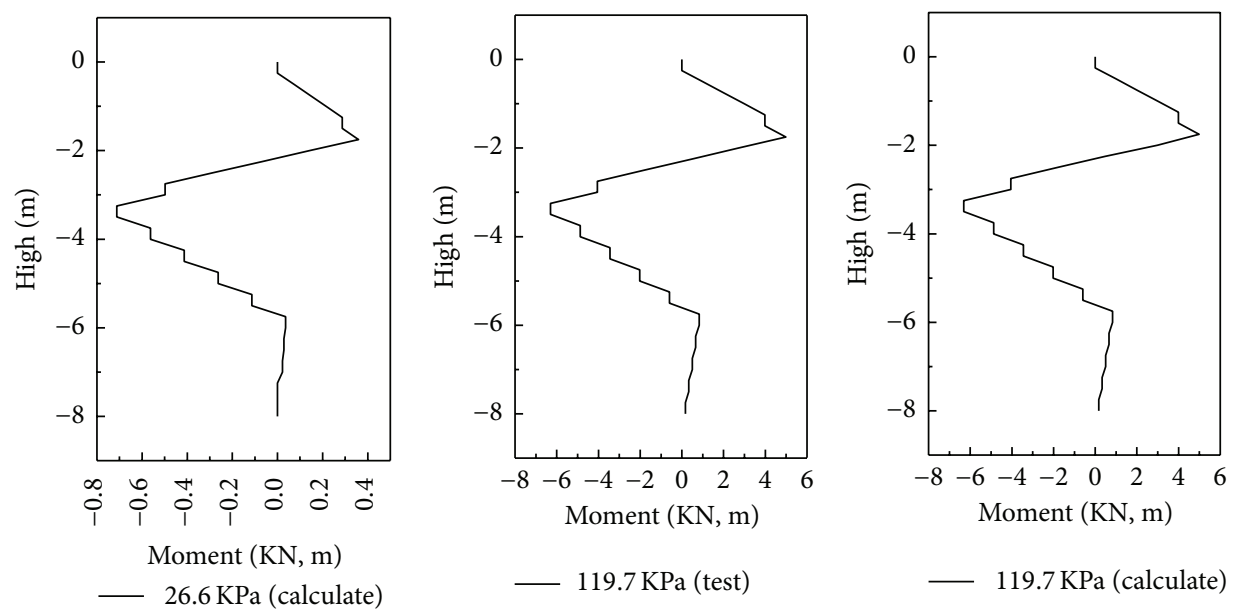

119.7 KPa (calculate)

(b) The second row of piles
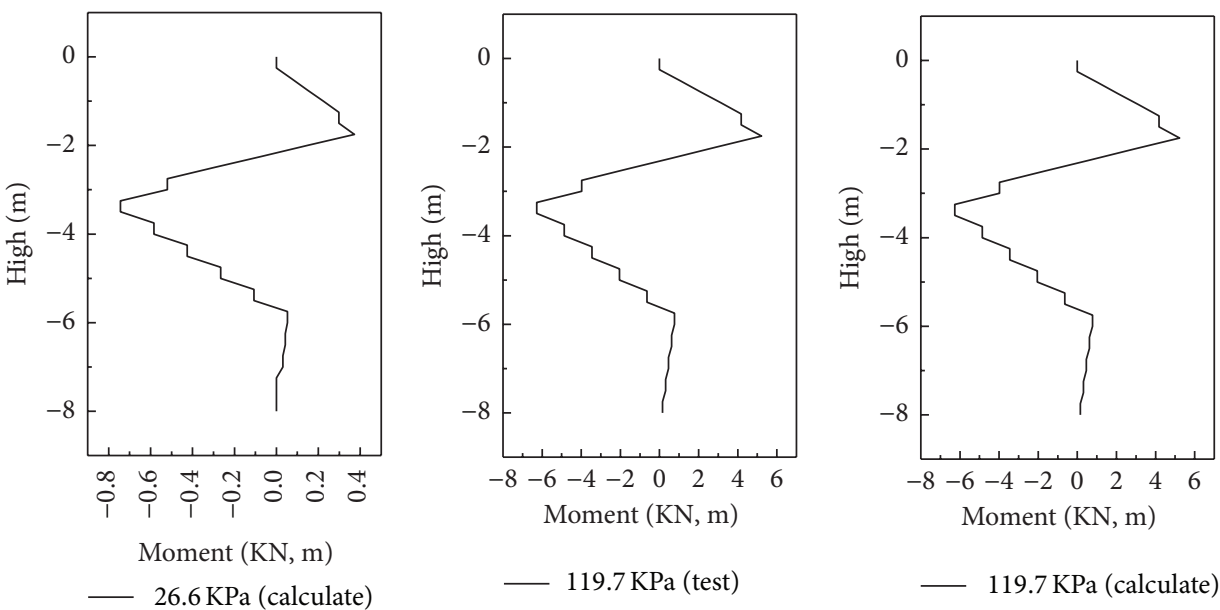

(c) The third row of piles

FIGURE 13: Comparative curves of the distribution of the pile model. 
in simulated field experiments under each grade of load, which shows that the theoretical approach demonstrated in this paper is feasible. From the figures, it can be detected that the results of the experiment are smaller than the bending moment and the rate of pile body displacement. This result occurs because, in most cases, while searching for solution to the Winkler Foundation Beam Model, the sheer force of the soil between piles is generally ignored. But for engineering design, the solution from theoretical approach adopted by the paper is simply safe; thus, it can satisfy design accuracy.

\section{Conclusion}

(1) This paper discusses an analytical solution to stress around a micropile. Displacement distribution under horizontal load is obtained according to the planar complex function theory. The defects found in the internal force analysis after applying uniform sections were addressed. The stress and displacement distribution were analyzed by utilizing the proposed analytical solution in the soil around the micropiles.

(2) Based on the Winkler Foundation Beam Model, we assumed that the soil around the micropiles stemmed from a series of independent springs. The rigidity coefficient of a spring is obtained using a planar solution. After that, based on the deflection curve differential equation of an Euler-Bernoulli beam, the pile deformation and internal force calculation methods of micropile composite structures under horizontal loads can be derived using two modes, which have provided theoretical guidance for engineering designs. On the one hand, one end is fixed with the other end sliding; on the other hand, both ends are fixed.

(3) By comparing the results obtained from on-site pile pushing tests, it is determined that the results obtained of the established theoretical approach are reasonably accurate and reliable.

\section{Conflict of Interests}

The authors declare that there is no conflict of interests regarding the publication of this paper.

\section{Acknowledgments}

This work was supported by the Fundamental Research Funds for the Central Universities (no. 2015YJS121). The authors would like to express their gratitude to the editors and reviewers for their constructive and helpful review comments.

\section{References}

[1] H. Juran, A. Benslimane, and D. A. Bruce, "Slope stabilization by micropile reinforcement," in Proceedings of the 7th International Symposium on Landslides, pp. 1718-1726, Trondheim, Norway, June 1996.
[2] D. A. Bruce, A. F. Dimillio, and I. Juran, "Introduction to micropiles: an international perspective," in Proceedings of the Conference on Geotechnical Engineering Division of the ASCE in Conjunction with the ASCE Convention, pp. 1-26, San Diego, Calif, USA, 1995.

[3] S.-G. Xiao, F. Xian, and H.-L. Wang, "Analytical method of internal forces of a combining micropiles structure," Rock and Soil Mechanics, vol. 31, no. 8, pp. 2553-2259, 2010.

[4] G. Russo, "Discussion: full-scale load tests on instrumented micropiles: technology and behavior," Geotechnical Engineering, vol. 157, pp. 127-135, 2004.

[5] R. Z. Moayed and S. A. Naeini, "Imrovement of loose sandy soil deposits using micropiles," KSCE Journal of Civil Engineering, vol. 16, no. 3, pp. 334-340, 2012.

[6] A. Ghorbani, H. Hasanzadehshooiili, E. Ghamari, and J. Medzvieckas, "Comprehensive three dimensional finite element analysis, parametric study and sensitivity analysis on the seismic performance of soil-micropile-superstructure interaction," Soil Dynamics and Earthquake Engineering, vol. 58, pp. 21-36, 2014.

[7] J. M. Duncan, L. T. Evans Jr., and P. S. K. Ooi, "Lateral load analysis of single piles and drilled shafts," Journal of Geotechnical Engineering, vol. 120, no. 6, pp. 1018-1033, 1994.

[8] R. L. Mokwa and J. M. Duncan, "Laterally loaded pile group effects and P-Y multipliers," Geotechnical Special Publication, vol. 113, pp. 728-742, 2001.

[9] M. J. Thompson and D. J. White, "Design of slope reinforcement with small-diameter piles," in Proceedings of the Advances in Earth Structures, pp. 67-73, ASCE, Shanghai, China, June 2006.

[10] R. Cantoni, T. Collotta, and V. N. Ghionna, "A design method for reticulated micropiles structure in sliding slope," Ground Engineering, vol. 22, no. 1, pp. 41-47, 1989.

[11] P. R. Macklin, D. Berger, W. Zietlow, W. Herring, and J. Cullen, "Case history: micropile use for temporary excavation support," in Proceedings of Sessions of the Geosupport Conference: Innovation and Cooperation in Geo, pp. 653-661, Geotechnical Special Publication, ASCE, Reston, Va, USA, January 2004.

[12] J. Feng, D.-P. Zhou, N. Jiang, and T. Yang, "Model for calculation of internal force of micropile system to reinforce bedding rock slope," Chinese Journal of Rock Mechanics and Engineering, vol. 25, no. 2, pp. 284-288, 2006.

[13] D. A. Brown and C.-F. Shie, "Numerical experiments into group effects on the response of piles to lateral loading," Computers and Geotechnics, vol. 10, no. 3, pp. 211-230, 1990.

[14] S. P. Timoshenko and J. N. Goodier, Theory of Elasticity, McGraw-Hill, New York, NY, USA, 1970.

[15] A. Verruijt, "Deformations of an elastic half plane with a circular cavity," International Journal of Solids and Structures, vol. 35, no. 21, pp. 2795-2804, 1998.

[16] O. E. Strack and A. Verruijt, "A complex variable solution for a deforming buoyant tunnel in a heavy elastic half-plane," International Journal for Numerical and Analytical Methods in Geomechanics, vol. 26, no. 12, pp. 1235-1252, 2002.

[17] A. Z. Lv and L. Q. Zhang, Underground Tunnel Complex Variable Method of Mechanical Analysis, Science Press, Beijing, China, 2007.

[18] P. D. Zhou, H. L. Wang, and H. W. Sun, "Micropile composite structure and its design theory," Chinese Journal of Rock Mechanics and Engineering, vol. 28, no. 7, pp. 1353-1361, 2009.

[19] F. Baguelin, R. Frank, and Y. H. Said, "Theoretical study of lateral reaction mechanism of piles," Geotechnique, vol. 27, no. 3, pp. 405-433, 1977. 


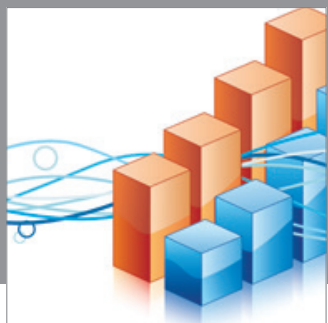

Advances in

Operations Research

mansans

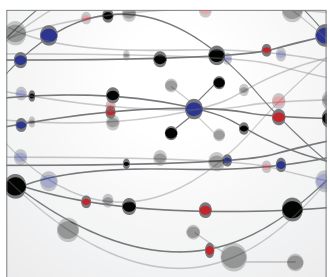

The Scientific World Journal
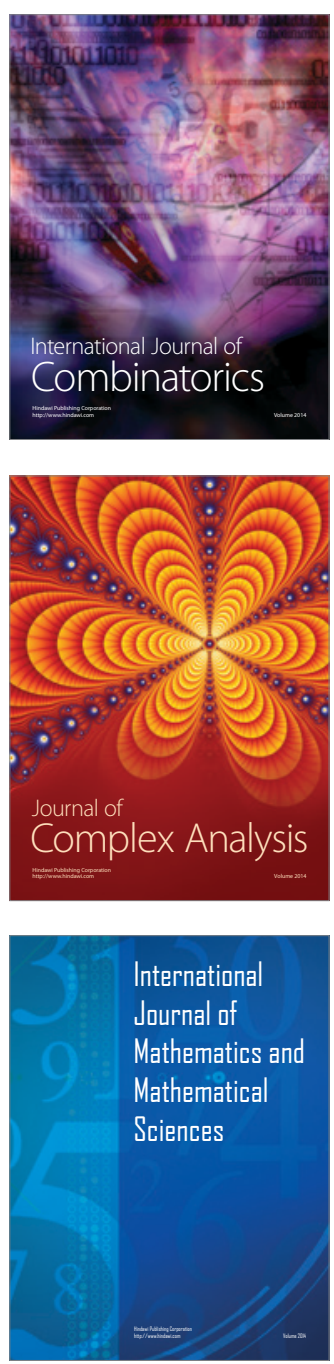
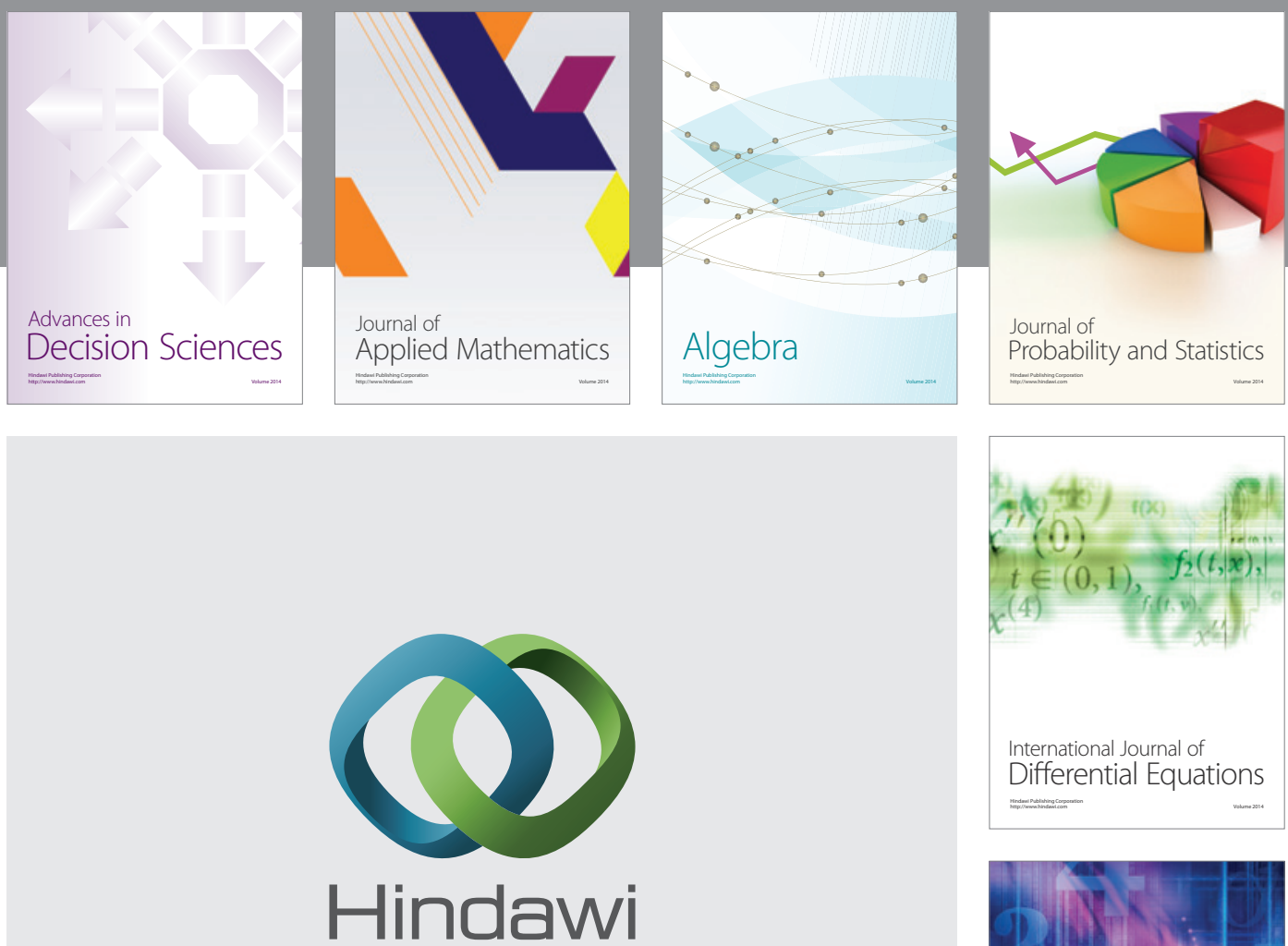

Submit your manuscripts at http://www.hindawi.com
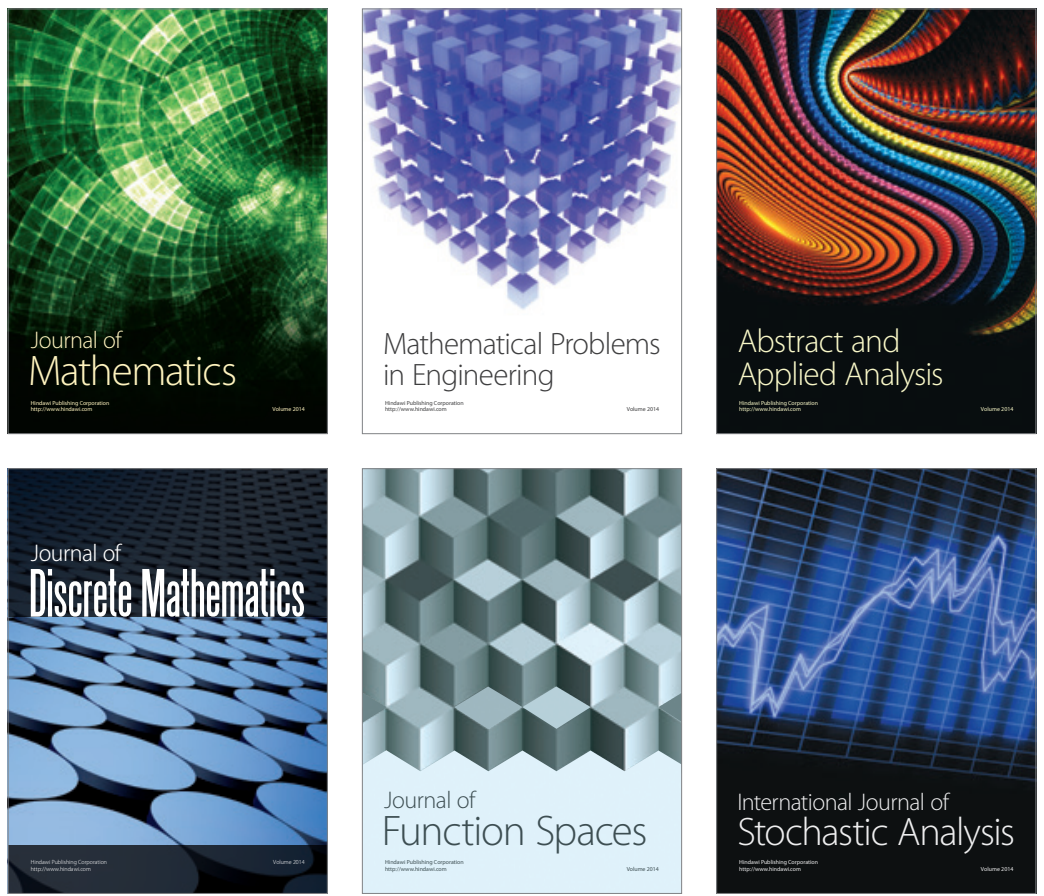

Journal of

Function Spaces

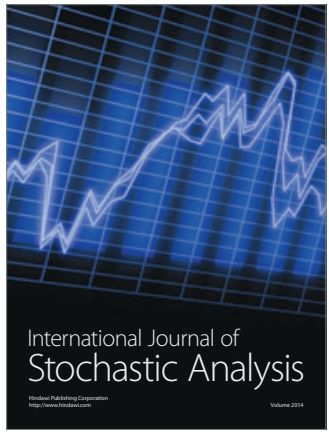

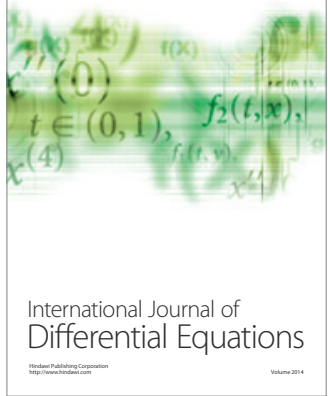
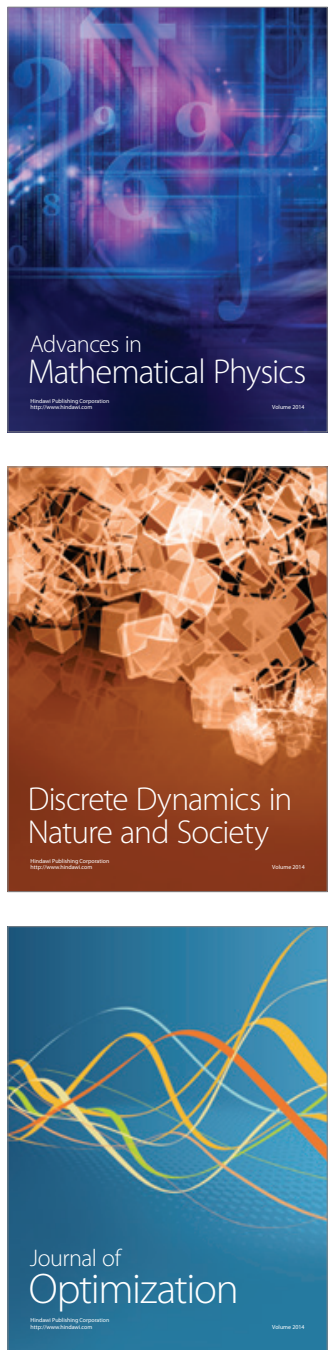